\title{
Effects of an Intervention Program on Interaction and Bodily Emotional Traces in Adults with Congenital Deafblindness and an Intellectual Disability
}

\author{
Kitty A. Bloeming-Wolbrink, Marleen Janssen, \\ Wied A.J.J.M. Ruijssenaars, J. Marianne Riksen-Walraven
}

\section{Acknowledgements}

We would like to acknowledge the contributions of Joke ter Maat, Lisanne van den Bovenkamp, and the staff and clients of Royal Dutch Visio, the Netherlands. We would also like to acknowledge the contributions of students from the University of Groningen and the Alfa-college in Groningen, the Netherlands. We would like to acknowledge the contributions of Mark Huisman, Ilse Stellingwerf, Ninke van Timmeren, and Maartje Hofman.

This research was funded by Royal Dutch Visio, and by the University of Groningen, Department of Special Needs Education and Youth Care. The funding bodies did not impose any restrictions on free access to or publications of the research data. There was no conflict of interest. 


\begin{abstract}
Interaction with people with congenital deafblindness (CDB) and an intellectual disability (ID), and recognition of their often unconventional expressions, is complex. In this study,

the effects of a two-phase intervention program intended to foster harmonious interaction and the use and recognition of expressions based on a bodily emotional trace (BET) were examined. Five adults with $\mathrm{CDB}$ and an ID, and ten of their caregivers participated in the study. A multiple-baseline design was used. Target behaviours were attention by caregiver, attention by participant, confirmation by caregiver, mutual affective involvement, quality of interaction, participant expressions based on a BET, and participant expressions based on a BET recognised by the caregiver. Overall, the results tend to be positive. However, some of the changes were minimal and the results varied considerably among participants. The results of this study suggest that it is possible to foster harmonious interaction and the use and recognition of expressions based on a BET in adults with CDB and an ID.
\end{abstract}

\title{
Keywords
}

Adults, bodily emotional traces, congenital deafblindness, focus group, intellectual disability, interaction. 


\section{Introduction}

Having harmonious interactions with others fosters well-being and improves the functioning of people of all ages (Diamond \& Aspinwall, 2003; Sroufe, 1995; Trevarthen \& Aitken, 2001). Infants have biologically founded capacities for social interaction (Aitken \& Trevarthen, 1997), which is defined as the process through which two individuals mutually influence each other's behaviour (Bjerkan, 1996; Janssen, Riksen-Walraven, \& Van Dijk, 2003a).

From childhood on, vision and hearing play important roles in social interaction, as is evident in eye-gaze, smiling, and reactions to acoustic signals similar to the human voice (Pérez-Pereira \& Conti-Ramsden, 1999). Vision and hearing cannot be addressed in the same way in interactions with people with congenital deafblindness (CDB). It is therefore necessary to address other senses, like the tactile modality.

People with CDB mainly experience the world through their proximal senses, often resulting in expressions that are atypical for seeing and hearing people. These expressions can be stereotypical and idiosyncratic (Bjerkan, 1996), and difficult for their communication partners to understand. Expressions made by people who have an intellectual disability (ID) in addition to CDB are often even more idiosyncratic and subtle, and are not always used consistently. This makes it very hard to notice and interpret these expressions, complicating interaction and subsequent qualitative communication. Qualitative communication is assumed to be based on harmonious interactions.

Moreover, communication is facilitated by a history of shared experiences. Adults with CDB and an ID who live in residential settings meet many different communication partners, which severely limits the construction of a history of shared experiences to communicate about. In short: establishing harmonious interaction and subsequent qualitative communication with people with CDB and an ID is very difficult (Bloeming-Wolbrink, Janssen, Ruijssenaars, Menke, \& Riksen-Walraven, 2015; Bruce, 2005; Dalby et al., 2009; Damen, Janssen, Huisman, Ruijssenaars, \& Schuengel, 2014; Dammeyer, 2010; Hart, 2010; Janssen et al., 2003a; Martens, Janssen, Ruijssenaars, \& Riksen-Walraven, 2014). Communication partners (e.g. caregivers, parents, teachers) need high levels of sensitivity, special insights, and considerable skills to establish harmonious interaction and qualitative communication with people with CDB and an ID (Janssen, Riksen-Walraven, \& Van Dijk, 2003b).

Several intervention studies have shown that coaching communication partners has positive effects on interaction and/or communication with people with CDB (e.g. Damen, Janssen, Ruijssenaars, \& Schuengel, 2015; Janssen et al., 2003b; Martens, Janssen, Ruijssenaars, Huisman, \& Riksen-Walraven, 2014a; Martens, Janssen, Ruijssenaars, Huisman, \& Riksen-Walraven, 2014b). Consequently, it is worthwhile to also put efforts into coaching 
communication partners to improve their interaction and communication with people with CDB and an ID.

People with CDB mainly experience the world through bodily-tactile experiences. When they think about these experiences, their thoughts are often reflected in bodily expressions such as touching a location on the body, making a movement, or replicating a sensation. Such bodily expressions of memories are based on a bodily emotional trace (BET). These expressions are typically neither social nor communicative when they emerge (Daelman et al., 2001), but they do show that something is going on in the mind of the person with CDB, and they may give important insights into how that person experiences the world and reflects on earlier experiences (Daelman, 2003).

Recognising these idiosyncratic expressions is useful for the partner in the meaningmaking process and is thus valuable for communication, in which information is conveyed to and received and interpreted from others (Rowland, 2009). According to Johnson (2008), the human "mind" cannot exist apart from embodiment. What and how humans experience, feel, think, value, and act is shaped by embodiment (Johnson, 2008). This is very clear in people with CDB and an ID. Training their communication partners to recognise and use BETs might provide insights into how a person with CDB and an ID reflects upon the world, thus helping the communication partners recognise and add meaning to idiosyncratic expressions.

The present study constitutes the second part of the broader Project CHANGE, an ongoing project that aims to improve interaction and communication in adults with CDB and an ID. The first part of Project CHANGE (reported in an earlier paper; Bloeming-Wolbrink et al., 2015) focused on the effects of a general improvement in the life circumstances of adults with $\mathrm{CDB}$ and an ID and the general training and coaching given to their caregivers on the quality of their interaction and expressive communication.

The goal of the present study - the second part of Project CHANGE - was to examine the effects of a two-phase intervention program for caregivers working with adults with CDB and an ID. It is specifically aimed at fostering harmonious interactions (Phase I) and the use and recognition of participant expressions based on a BET (Phase II). During Phase I, it was attempted to improve the interactive competence of the adults with CDB by coaching their caregivers to respond appropriately to their interactive behaviours. During Phase II it was attempted to improve the use and recognition of participants' expressions based on a BET by coaching their caregivers to introduce something new in a routine situation and to strengthen the experience of the participant (e.g. by repeating parts of the experience).

The present study aims to answer three research questions:

1) To what extent does the intervention increase the quality of interaction and, more particularly, the occurrence of attention by the caregiver, attention by the participant, confirmation by the caregiver, and affective involvement between participant and caregiver? 2) To what extent does the intervention increase the number of expressions 
based on a BET made by the participant and the recognition of these expressions by the caregiver?

3) To what extent do the effects of the intervention endure after completion of the intervention?

\section{Method}

\section{Participants and Setting}

The study was conducted at a facility for people with intellectual and sensory disabilities in the Netherlands. Five adults with CDB and an ID ("participants") took part in the study: four men and one woman. They differed with regard to age and the degree of sensory disability. Table 1 presents an overview of relevant participant characteristics.

\section{Table 1}

Participant Characteristics at the Start of the Intervention Program

\begin{tabular}{llllll}
\hline $\begin{array}{l}\text { Participant } \\
\text { code }\end{array}$ & Gender & $\begin{array}{l}\text { Age } \\
\text { (years) }\end{array}$ & $\begin{array}{l}\text { SRZ } \\
\text { score }\end{array}$ & Visual disability & \\
\hline P1 & Female & 42 & $3-$ & Totally blind & Hearing disabilityc \\
P2 & Male & 53 & $3-$ & Blind & Proderate/severe hearing loss \\
P3 & Male & 42 & 3 & Totally blind & $\begin{array}{l}\text { Hearing loss; unclear whether } \\
\text { there is residual hearing }\end{array}$ \\
P4 & Male & 18 & $3-$ & Blind & Profound hearing loss \\
P5 & Male & 43 & 3 & Blind & Profound hearing loss \\
\hline
\end{tabular}

a SRZ POP-EM score of 3 or 3-is appropriate in the case of a profound intellectual disability

b Totally blind: no light perception; Blind: blind with light perception

c Moderate hearing loss: 41-60dB; Severe hearing loss: 61-80dB; Profound hearing loss: $\geq 81 \mathrm{~dB}$

Prior to the start of Project CHANGE, none of the participants had received deafblind education or been educated with a consistent approach that took their deafblindness into account. The main focus in their education had been on the ID.

Ten caregivers (all female) were included in the study. Their ages ranged from 20 to 55 years $(M=36.4)$. Four caregivers had a Bachelor's degree, and the other six caregivers had had vocational training. They had 2 to 28 years $(M=12.6)$ of experience in working with persons with ID, and 1 to 17 years $(M=4.6)$ of experience in working with persons with deafblindness.

Each participant formed pairs, at random, with two caregivers, resulting in ten pairs. Two pairs were excluded from analysis, due to illness of the caregiver and the poor quality of video 
recordings. Thus, results are presented for three participants with two caregivers (A and B) and for two participants with one caregiver.

The study was approved by the board of the facility. Written informed consent was obtained from the participants' legal representatives. Verbal informed consent was obtained from the caregivers. To protect the participants' identities, each participant is identified by a number in this article.

\section{Research Design}

This study followed a multiple-baseline design across subjects (see Figure 1). The baseline becomes longer for each consecutive participant, with a minimum length of four baseline sessions (Barlow, Nock, \& Hersen, 2009) and a maximum of 12. The two-phase intervention program had a total duration of 15 weeks: 9 for Phase I (interaction training) and 6 for Phase II (BET training). These two phases were complementary. The design was time-based: Phase II began directly after finishing Phase I, regardless of the Phase I results. The study ended with follow-up sessions at 3, 7, and 11 weeks after the end of the intervention program.

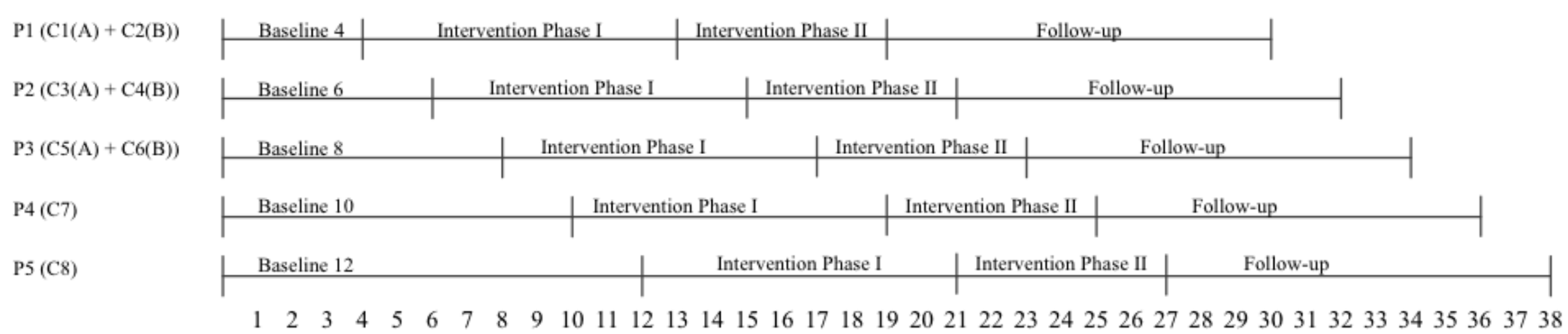

Figure 1. Duration of the effect study (in weeks) per participant and caregiver.

\section{Intervention Program}

The intervention program consists of Phase I: interaction training, and Phase II: BET training. The outline of the coaching in Phase I was based on the diagnostic intervention model CONTACT, which is used to foster harmonious interactions between children with deafblindness and their educators. The model is based on theoretical aspects from attachment and intersubjectivity theories (see Janssen et al., 2003a).

The intervention program applied in this study adds a second Phase, a BET training, based on theoretical aspects of embodiment theory (Johnson, 2008). Phase II of the intervention program focused on increasing the use and recognition of participant expressions based on a BET.

The intervention program, consisting of seven subsequent steps (Phase I: step 1-4, Phase II: step 5-7), was applied by a coach (the first author). As shown in Figure 2, the intervention 
program included five 45-minute coaching sessions registered in a protocol, resulting in a total of 3 hours and 45 minutes of information transfer and video-feedback per caregiver.

Intervention

Phase I: Interaction training

Coaching

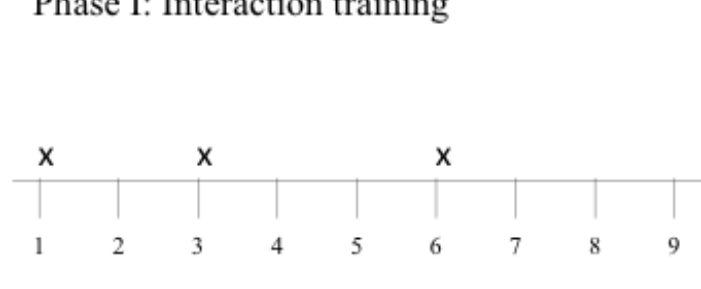

Phase II: BET training

$x \quad x$

$x$

\begin{tabular}{llll|} 
& & $\mid$ & $\mid$ \\
12 & 13 & 14 & 15
\end{tabular}

Figure 2. Coaching sessions across weeks during the intervention program.

The intervention protocol ${ }^{1}$ :

1. Determining the question. The caregivers requested coaching for questions concerning interaction.

2. Clarifying the question. The coach consulted the caregivers in order to specify the questions for interaction training. Examples include: how can I recognise the participant's initiatives and confirm these?; how can I share emotions with the participant in a tactile way?

3. Interaction analysis. The coach analysed video recordings of interaction to translate the questions for interaction training into intervention aims for Phase I of the intervention. Example: the caregiver confirms the participant's initiative by repeating it tactilely.

4. Implementing intervention focusing on interaction. The three coaching sessions included information transfer and video-feedback. The intervention aims, other aspects of interaction, and the interaction context were addressed. Examples of aspects of the interaction context discussed include: changing the caregiver's position during a foot massage to make the participant more comfortable or changing the caregiver's position while baking cookies so that she could observe the participant's face.

5. BET analysis. The coach analysed video recordings for preparing step 6 . The focus was on possibilities for introducing something new in the routine situation, since this seems to evoke BETs and expressions based on a BET (Bloeming-Wolbrink, 2007). Looking for ways to strengthen the experience for the participant, for example repeating parts of the experience, was another focus in the analysis.

\footnotetext{
${ }^{1}$ The exact content of the intervention program is available from the first author.
} 
6. Implementing intervention focusing on BETs. The two coaching sessions included information transfer and video-feedback. The definition and importance of the BET concept, and ways to strengthen an experience were discussed in the first coaching session of Phase II, illustrated with video-clips of persons with CDB. It was discussed which new topic could be introduced in the routine situation. Example: intentionally leaving the butter out while baking cookies. In the last coaching session video-feedback was used to observe expressions based on a BET, and to decide whether changes in the new topic were needed (e.g. to clarify the situation for the participant or to arouse the participant's interest).

7. Evaluation. The intervention is evaluated with regard to the intervention aims set and the satisfaction of the caregivers with the intervention process.

\section{Data Collection}

To examine the effects of the intervention program on interaction and BETs, 20-minute video recordings were made weekly during baseline and the intervention phases. During follow-up, they were made 3,7 , and 11 weeks after the end of the intervention. Throughout the study, each participant-caregiver pair was recorded during the same activity, an activity in which both parties felt comfortable (based on the caregiver's impression), and which guaranteed that it could always be performed (e.g. baking cookies, interacting on the waterbed).

The recordings of each pair were all made on the same day of the week and at the same time of day, based on the caregiver's working schedule and the time of the day the activity could be performed. Caregivers' coaching sessions were pre-planned for weeks 1, 3, 6, 10, and 12 of the 15-week intervention program (see Figure 2). In case of unanticipated circumstances, like illness, recordings or coaching sessions were rescheduled.

\section{Instruments and Measures}

\section{Interaction: Coding.}

Observation categories. To measure the effect of the intervention program on interaction, four categories of interactive behaviour were used (adopted from Janssen et al., 2003a):

1a) Attention by caregiver: focus on interaction partner, interaction content, people and/or objects within the interaction context;

1b) Attention by participant (see 1a);

2) Confirmation by caregiver: clear acknowledgement that an initiative has been noticed and recognised;

3) Affective involvement: mutual sharing of emotions between caregiver and participant. 
Observation procedure and scoring. Five-minute fragments (4-12 for baseline, 15 for intervention, 3 for follow-up) with a fixed starting point per pair were selected from the 20minute recordings. The fixed starting point was chosen to maximise the comparability of the fragments. Examples of fixed starting points are offering the pastry bowl to the participant and taking off the participant's shoes.

Observers coded the videos on an observation form with 10 -second intervals. If attention by participant and caregiver was observed for $\geq 6$ seconds during the interval, it was coded 1 ; otherwise, it was coded 0 . Confirmation by caregiver and affective involvement were coded 1 if observed at least once during an interval; if not, they were coded 0 . For each category, an interval was excluded from coding if the information needed to code that category was lacking (e.g. if a face was not visible, affective involvement could not be observed). The occurrence of the categories of interactive behaviour per five-minute fragment was expressed in a number, calculated by counting the number of intervals with code 1 . The maximum score was 30 . In case of intervals excluded from coding, the number of intervals with code 1 was divided by the total number of intervals with code 1 and 0 , and multiplied by 30 .

Five trained observers, current or graduated Bachelor's and Master's students in the social sciences, coded the videos. To control for observer drift, the videos were coded at random by the observers. Prior to each observation session, each observer read the definition of the categories and the operationalisation of the participant's interactive behaviour. The operationalisation of the participant's interactive behaviour was based on videotaped observations of various interaction situations.

Inter-rater reliability. Prior to formal data collection, the observers were trained to reach $80 \%$ inter-rater reliability for the occurrence of the interactive behaviours for three training videos per participant-caregiver pair. The training videos were not used for the actual coding. Two observers were trained for each participant.

When coding the research recordings, the first observer coded all of a participant's recordings; the second observer coded $\geq 25 \%$ of them (Barlow et al., 2009), which were selected at random. Inter-rater reliability was calculated using percentage agreement and Kappa, following Prain, McVilly, and Ramcharan (2012). Percentage agreement was calculated by dividing the number of agreements on occurrences and non-occurrences by the total number of agreements and disagreements, and multiplying the result by 100 (Brown \& Snell, 1993).

Inter-rater reliability was calculated across measurements and participants. The percentage agreement and Kappa scores were $96.8 \%$ and .84 for attention by caregiver, $91.4 \%$ and .83 for attention by participant, $97.0 \%$ and .74 for confirmation by caregiver, and $99.4 \%$ and .44 for affective involvement. The Kappa score for affective involvement implies that the results for this category should be interpreted with great caution. 
Interaction: Focus group. To qualitatively measure the effect of the intervention program, the quality of interaction in the participant-caregiver pairs was discussed in three focus group meetings, with the first author as moderator. Four people participated in the focus group: a professor in Special Needs Education with a focus on deafblindness (the second author), another professor in Special Needs Education (the third author), and two Master's students in Special Needs Education. For each participant-caregiver pair, four coded fiveminute fragments were selected: one for baseline, two for the ends of the intervention phases, and one for follow-up. The fragments were offered to the focus group members in a random order per participant-caregiver pair, in order to avoid observer drift.

The discussion of the quality of interaction for each pair started with a short introduction of the participant and the activity. The four fragments were watched with short breaks in between, during which the focus group members were asked to react in a few words about the quality of interaction. After finishing all fragments of a pair, a longer discussion began about the quality of interaction in general and different aspects of it: togetherness, turn taking, closeness, initiatives, and answers.

Subjective judgement. After finishing the discussion for a participant-caregiver pair, the four focus group members were asked to make independent judgements about the quality of interaction in each fragment. Judgements were made on a scale ranging from 1 (not good) to 4 (very good). Focus group members were also asked to rank the quality of interaction in the four fragments. The individual scores and rankings were combined into an overall score and ranking for each fragment, by summing the individual scores or rankings and dividing the total number by four.

Content analysis. Focus group meetings were audiotaped and then transcribed. Eleven important concepts (attention, attunement, answers, involvement, communication, contact, initiatives, interaction, reacting, togetherness, and closeness) were included in the analysis. These concepts were derived from the categories of interactive behaviour (Janssen et al., 2003a), the questions asked by the moderator, and concepts often mentioned by the focus group members. Inclusion criteria for the concepts were identified. Information about the inclusion criteria per concept is available from the first author.

Semantic content analysis was performed, in which concepts are classified according to their meaning. Semantic content analysis has three forms, one of which (assertion analysis) was performed here. Assertion analysis includes both the frequency of naming the concepts and the nature of the context in which the concepts are used (positive, neutral, negative) (Janis, 1965, in Stewart, Shamdasani, \& Rook, 2007). A Master's student performed the analysis and coded the concepts in the transcriptions. Each concept received a positive (1), negative $(-1)$, or neutral $(0)$ characterisation, resulting in a score that reflected the judgement of the quality of interaction for each fragment. 


\section{Bodily Emotional Traces.}

Observation categories and criteria. The effect of the intervention program on the use and recognition of participants' expressions based on BETs was measured by coding the expressions the participants made and coding whether the caregiver noticed them. Three criteria were set to identify these expressions: it is an expression of thinking; it is judged to be referring to an earlier experience in a bodily way; and, when making the expression, the person is not paying attention to the surroundings (Stellingwerf, 2012). These criteria were operationalised for each participant, meaning that concrete behaviours were described.

observation procedure and scoring. For each participant, one participant-caregiver pair was included in the analysis. The pairs were selected at random. Six 10-minute fragments were selected from the 20-minute recordings: one from baseline, two from each of the intervention phases, and one from follow-up. The 10-minute length was chosen because it was expected that expressions based on a BET would occur often enough in this period to make it possible to compare the number of expressions in the different phases. If possible, the caregiver's introduction of the new topic was taken as the starting point of the 10-minute analysis. When necessary, in order to analyse 10 minutes of the recordings, the starting point was set before the introduction of the new topic.

Two observers independently coded each fragment on a specially designed observation form. Samples of 15-second intervals were used. Per interval, expressions based on a BET were coded 1 if observed at least once, and coded 0 if not observed. Expressions continuing in subsequent intervals were coded 1 in the first interval in which they were observed, and coded 0 in the subsequent intervals, to avoid counting a single expression twice. A note was made on the observation form in these cases. In the case of a code 1 , the expression based on a BET was described on the observation form.

After the observers finished independently coding a participant's six fragments, they discussed their scores and arrived at a consensus score. An overall score, reflecting the occurrence of expressions based on a BET in the 10-minute episode, was calculated by summing the number of intervals coded 1.

For each 15-second interval coded 1, the observer noted whether or not the caregiver recognised the expression. The observer carefully described the behaviour of the caregiver that made her believe the caregiver did or did not recognise the expression. A percentage score was calculated by dividing the number of expressions recognised by the caregiver by the total number of expressions in the fragment, multiplied by $100 \%$.

Two trained observers, one current and one graduated Master's student in Special Needs Education, coded the videos. To control for observer drift, the videos were presented at random to the observers. Prior to each observation session, the observers read the manual for the participant they observed. The manual consisted of the three criteria for identifying expressions based on a BET and the operationalisation of these criteria (i.e. the description of 
concrete behaviours by the participant). Examples for the criterion "it is an expression of thinking" are tapping with the finger right beside the eye, freezing, or turning the head backwards. Examples for the criterion "it is judged to be referring to an earlier experience in a bodily way" are making a movement that resembles the movement in an earlier experience or touching a location on the body that was touched during the earlier experience. Examples for the criterion "the person is not paying attention to the surroundings" are the participant closing his or her hand or not responding to questions.

Inter-rater reliability. Prior to formal data collection, the observers were trained until $80 \%$ inter-rater reliability was reached for the occurrence of expressions based on a BET for three training videos per participant. The training videos were not used for the actual coding. Following the recommendation of Prain et al. (2012), we chose to use consensus coding because the participants' expressions were expected to be highly idiosyncratic and context dependent. The observers coded the research videos independently. During scoring, the observers noted the reasons when coding 1 . After the independent coding, the observers compared and discussed their scores and their justifications for them. This discussion resulted in a consensus score.

Inter-rater reliability for the actual research recordings was calculated using percentage agreement and Kappa. Inter-rater reliability was calculated across measurements and dyads for the occurrence of expressions based on a BET, between observers 1 and $2(99.6 \%$ and .90 ), between observer 1 and consensus score (99.5\% and .87), and between observer 2 and consensus score (99.9\% and .98). Both percentage agreement and Kappa were good, even when comparing observers 1 and 2.

Social validity. To ensure the clinical significance of the intervention program, the participating caregivers were actively involved in setting and evaluating their own intervention aims for interaction and in choosing which activity to perform with the participants. After finishing the study, they were asked to rate components of the intervention program on a 5-point scale, on an adapted version of the Social Validity Scale (BloemingWolbrink \& Janssen, 2010, following Seys, 1987). Components were subjective effectiveness (e.g. "the idea of coaching caregivers in order to improve the interaction between participants and caregivers is very bad/bad/sufficient/good/very good"), effectiveness of single components of the intervention (e.g. "recognising expressions based on a BET was very hard/hard/well performable/good/very good"), and workability (e.g. "I found that the presence of a video camera in the group home was very bad/bad/sufficient/good/very good"). All the caregivers ( $\mathrm{n}=8$ ) returned the questionnaire.

\section{Data analysis}

Given the relatively small number of observations and the serial dependencies in the data, statistical tests such as time series methods are not feasible. Therefore, descriptive and visual 
analysis were used as the most important analysis method in this study. This method is commonly used in single subject experimental research (Horner, Carr, Halle, Odom, \& Wolery, 2005; Nourbakhsh \& Ottenbacher, 1994).

\section{Results}

\section{Effects on Interaction: Coding}

Table 2 presents an overview of the mean occurrence, range, and standard deviation of the categories of interactive behaviour (i.e. attention by caregiver and affective involvement) across the four phases of the study for each participant. Figures 3 and 4 present the results for the categories of interactive behaviour, attention by participant, and confirmation by participant. ${ }^{2}$ The maximum score was 30 , representing the total number of intervals in a fiveminute fragment.

\section{Table 2}

Attention by Caregiver and Affective Involvement over Time

Attention by Caregiver

\begin{tabular}{|c|c|c|c|c|c|c|c|c|c|c|c|c|}
\hline & \multicolumn{3}{|c|}{ P1 } & \multicolumn{3}{|c|}{ P2 } & \multicolumn{3}{|c|}{ P3 } & \multirow{2}{*}{$\begin{array}{c}\text { P4 } \\
\text { Score }\end{array}$} & \multirow{2}{*}{$\begin{array}{c}\text { P5 } \\
\text { Score }\end{array}$} \\
\hline & & A & B & Score & A & B & Score & A & B & Score & & \\
\hline \multirow[t]{3}{*}{ Baseline } & Mean & 27.8 & 29.8 & 28.8 & 26.5 & 15 & 20.8 & 29.8 & 29.8 & 29.8 & 29.9 & 14.3 \\
\hline & Range & $25-30$ & $29-30$ & $25-30$ & $25-28$ & $6-28$ & $6-28$ & $29-30$ & $29-30$ & $29-30$ & 29-30 & $9-26$ \\
\hline & SD & 2.63 & 0.50 & 2.05 & 1.22 & 8.29 & 8.25 & 0.46 & 0.46 & 0.45 & 0.32 & 4.97 \\
\hline Intervention & Mean & 29.6 & 29.7 & 29.6 & 25.2 & 28.2 & 26.7 & 30 & 29.6 & 29.8 & 29.9 & 17.4 \\
\hline \multirow[t]{2}{*}{ Phase I } & Range & $28-30$ & $28-30$ & $28-30$ & $23-27$ & $25-30$ & $23-30$ & 30 & $28-30$ & $28-30$ & 29-30 & $12-25$ \\
\hline & SD & 0.73 & 0.71 & 0.70 & 1.39 & 1.64 & 2.14 & 0 & 0.73 & 0.55 & $\mathbf{0 . 3 3}$ & 4.00 \\
\hline Intervention & Mean & 30 & 28.7 & 29.3 & 25 & 28.2 & 26.6 & 30 & 29.3 & 29.7 & 30 & 29.3 \\
\hline \multirow[t]{2}{*}{ Phase II } & Range & 30 & $22-30$ & $22-30$ & $23-27$ & $26-29$ & 23-29 & 30 & $28-30$ & 28-30 & 30 & 26-30 \\
\hline & SD & 0 & 3.27 & 2.31 & 1.67 & 1.17 & 2.15 & 0 & 0.82 & 0.65 & $\mathbf{0}$ & 1.63 \\
\hline \multirow[t]{3}{*}{ Follow-Up } & Mean & 30 & 28 & 29 & 24.7 & 29 & 26.8 & 30 & 29 & 29.5 & 30 & 24 \\
\hline & Range & 30 & $27-29$ & $27-30$ & $23-27$ & $28-30$ & $23-30$ & 30 & $27-30$ & $27-30$ & 30 & $22-26$ \\
\hline & SD & 0 & 1.00 & 1.26 & 2.08 & 1.00 & 2.79 & 0 & 1.73 & 1.22 & $\mathbf{0}$ & 2.00 \\
\hline
\end{tabular}

\footnotetext{
${ }^{2}$ More detailed information about the results for the categories of interactive behaviour attention by participant and confirmation by participant is available from the first author.
} 
Affective Involvement

\begin{tabular}{llccccccccccc} 
& & & $\mathrm{P} 1$ & & & $\mathrm{P} 2$ & & & $\mathrm{P} 3$ & & P4 & P5 \\
& & $\mathrm{A}$ & $\mathrm{B}$ & $\mathrm{Score}$ & $\mathrm{A}$ & $\mathrm{B}$ & Score & $\mathrm{A}$ & $\mathrm{B}$ & Score & Score & Score \\
\hline Baseline & Mean & 0 & 0.3 & $\mathbf{0 . 1}$ & 0 & 0 & $\mathbf{0}$ & 0.1 & 0 & $\mathbf{0 . 1}$ & $\mathbf{0}$ & $\mathbf{0}$ \\
& Range & 0 & $0-1$ & $\mathbf{0 - 1}$ & 0 & 0 & $\mathbf{0}$ & $0-1$ & 0 & $\mathbf{0 - 1}$ & $\mathbf{0}$ & $\mathbf{0}$ \\
& SD & 0 & 0.50 & $\mathbf{0 . 3 5}$ & 0 & 0 & $\mathbf{0}$ & 0.35 & 0 & $\mathbf{0 . 2 5}$ & $\mathbf{0}$ & $\mathbf{0}$ \\
\hline Intervention & Mean & 0 & 0.1 & $\mathbf{0 . 1}$ & 0 & 0.2 & $\mathbf{0 . 1}$ & 0.2 & 0 & $\mathbf{0 . 1}$ & $\mathbf{0}$ & $\mathbf{0}$ \\
Phase I & Range & 0 & $0-1$ & $\mathbf{0 - 1}$ & 0 & $0-1$ & $\mathbf{0 - 1}$ & $0-1$ & 0 & $\mathbf{0 - 1}$ & $\mathbf{0}$ & $\mathbf{0}$ \\
& SD & 0 & 0.33 & $\mathbf{0 . 2 4}$ & 0 & 0.44 & $\mathbf{0 . 3 2}$ & 0.44 & 0 & $\mathbf{0 . 3 2}$ & $\mathbf{0}$ & $\mathbf{0}$ \\
\hline Intervention & Mean & 0 & 0.3 & $\mathbf{0 . 2}$ & 0 & 0.2 & $\mathbf{0 . 1}$ & 0 & 0 & $\mathbf{0}$ & $\mathbf{0}$ & $\mathbf{0}$ \\
Phase II & Range & 0 & $0-1$ & $\mathbf{0 - 1}$ & 0 & $0-1$ & $\mathbf{0 - 1}$ & 0 & 0 & $\mathbf{0}$ & $\mathbf{0}$ & $\mathbf{0}$ \\
& SD & 0 & 0.52 & $\mathbf{0 . 3 9}$ & 0 & 0.41 & $\mathbf{0 . 2 9}$ & 0 & 0 & $\mathbf{0}$ & $\mathbf{0}$ & $\mathbf{0}$ \\
\hline Follow-Up & Mean & 0 & 0 & $\mathbf{0}$ & 0 & 0.7 & $\mathbf{0 . 3}$ & 0.3 & 0 & $\mathbf{0 . 2}$ & $\mathbf{0 . 7}$ & $\mathbf{0}$ \\
& Range & 0 & 0 & $\mathbf{0}$ & 0 & $0-1$ & $\mathbf{0 - 1}$ & $0-1$ & 0 & $\mathbf{0 - 1}$ & $\mathbf{0 - 2}$ & $\mathbf{0}$ \\
& SD & 0 & 0 & $\mathbf{0}$ & 0 & 0.58 & $\mathbf{0 . 5 2}$ & 0.58 & 0 & $\mathbf{0 . 4 1}$ & $\mathbf{1 . 1 5}$ & $\mathbf{0}$ \\
\hline
\end{tabular}

Note. $\mathrm{SD}=$ standard deviation.

Attention by caregiver. For participants 1,3 , and 4, the mean occurrence of attention by caregiver was already high at baseline (28.8, 29.8, and 29.9, respectively), making only small improvements possible (see Table 2). For participants 2 and 5, however, the mean occurrence of attention by caregiver at baseline was 20.8 and 14.3, respectively. Large improvements for these participants were found, with a mean occurrence of 26.7 and 17.4, respectively, in Phase I, and a mean occurrence of 26.6 and 29.3, respectively, in Phase II. Also, a smaller range in scores was found during intervention for these participants, also reflected in a lower standard deviation.

Attention by participant. The line graphs in the right panel of Figure 3 demonstrate a large variability between the participants. For participant 4 , the occurrence was already high during baseline and stayed high with a few dips in Phase II and the follow-up phase. Figure 3 shows that occurrence increased for participants 2 and 5 during Phase I, but slightly decreased during Phase II, with a downward trend line. Occurrence during follow-up was variable: participant 5 had an upward trend line and participant 2 had a slightly downward trend line. Participant 1 had a downward trend line in the scores for Phase I and a strong upward trend line for Phase II because of a high peak in session 19. The occurrence of attention by the participant declined in the follow-up with a slight upward trend line. 


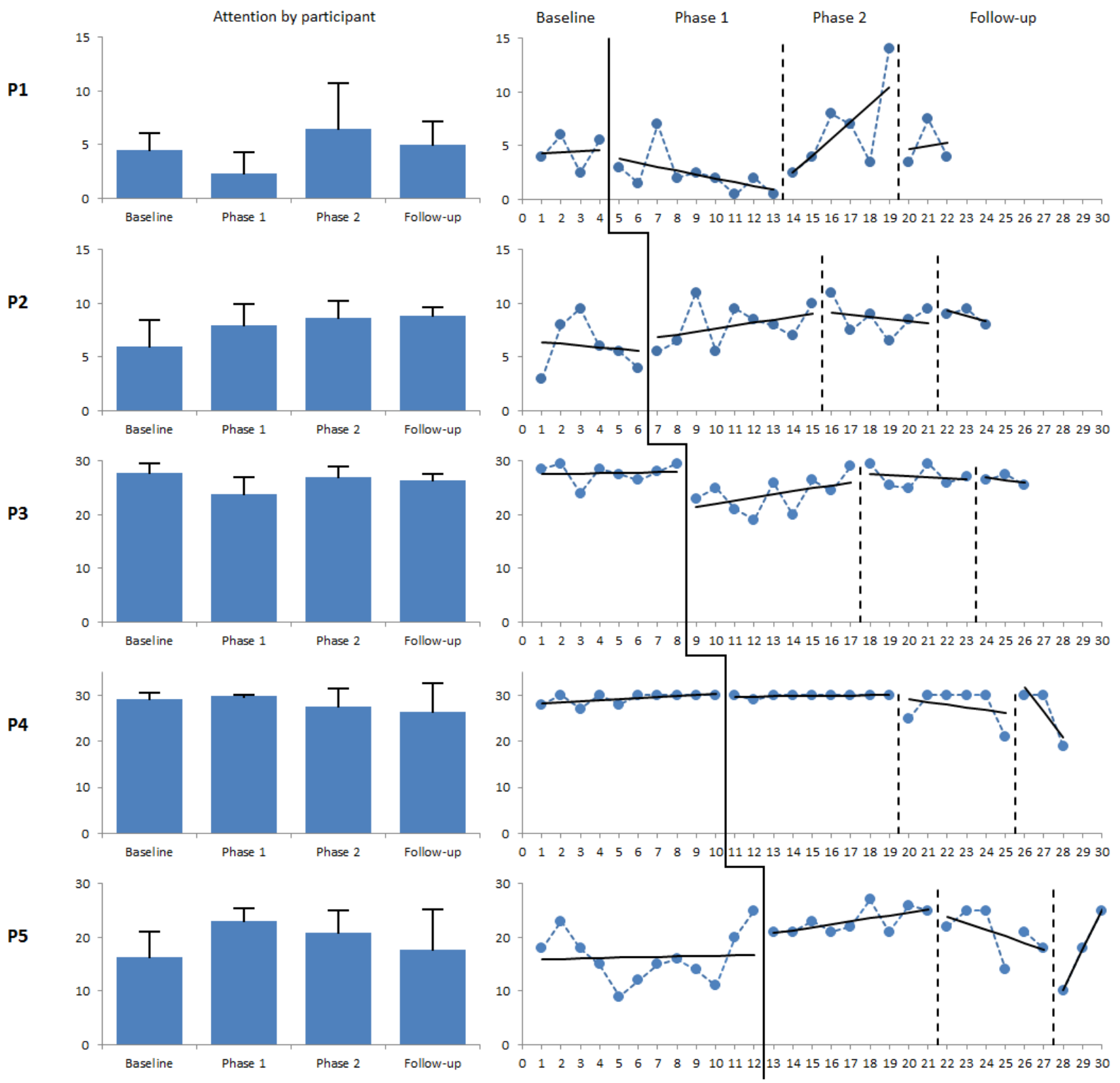

Figure 3. Attention by participant. Mean occurrence (number) across the entire phase for each of the four intervention conditions (left) and occurrence (number) during the separate observation sessions (right).

Confirmation by caregiver. Figure 4 shows the large variability within the different phases per participant and between the individual participants. For participant 4, confirmation by the caregiver occurred relatively more often than for the other participants. Remarkably, participant 4 started Phase I with a very high increase in the occurrence of confirmation, but the trend line unfortunately lowered during this phase. In the other phases, there was not much difference from the baseline.

The other participants had upward or steady trend lines in Phase I. In Phase II, the occurrence of confirmation was lower than in Phase I for all cases except participant 2. An 
upward trend line was also observed for participant 3. For participants 1 and 2, occurrence was higher during follow-up than during the other phases (unfortunately with a downward trend for participant 2). For the other three participants, occurrence during follow-up was higher than the occurrence in Phase II. A peak was found in session 24 for participant 3, but unfortunately a downward trend line for participants 3 and 4 was found.

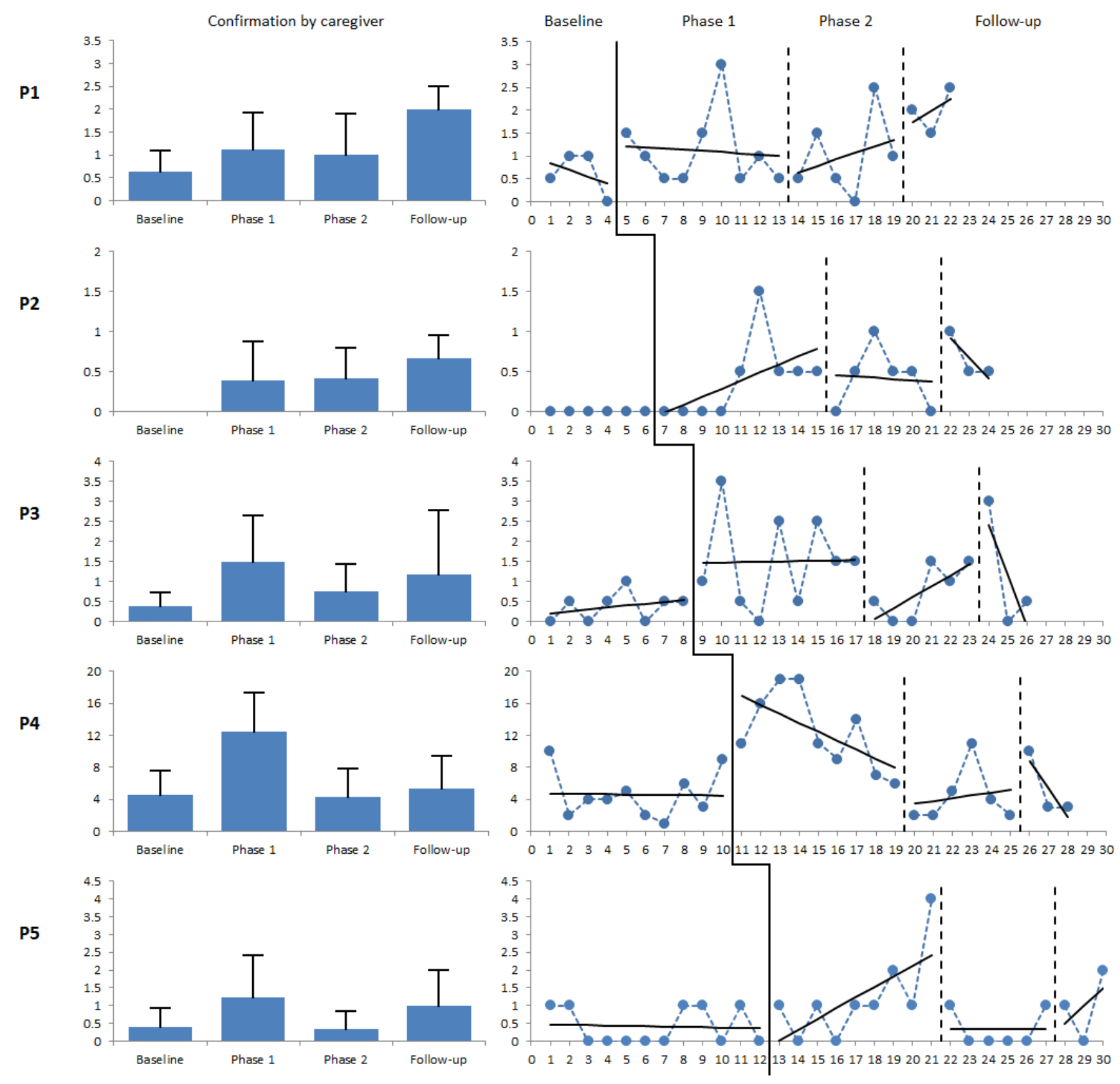

Figure 4. Confirmation by caregiver. Mean occurrence (number) across the entire phase for each of the four intervention conditions (left) and occurrence (number) during the separate observation sessions (right). 


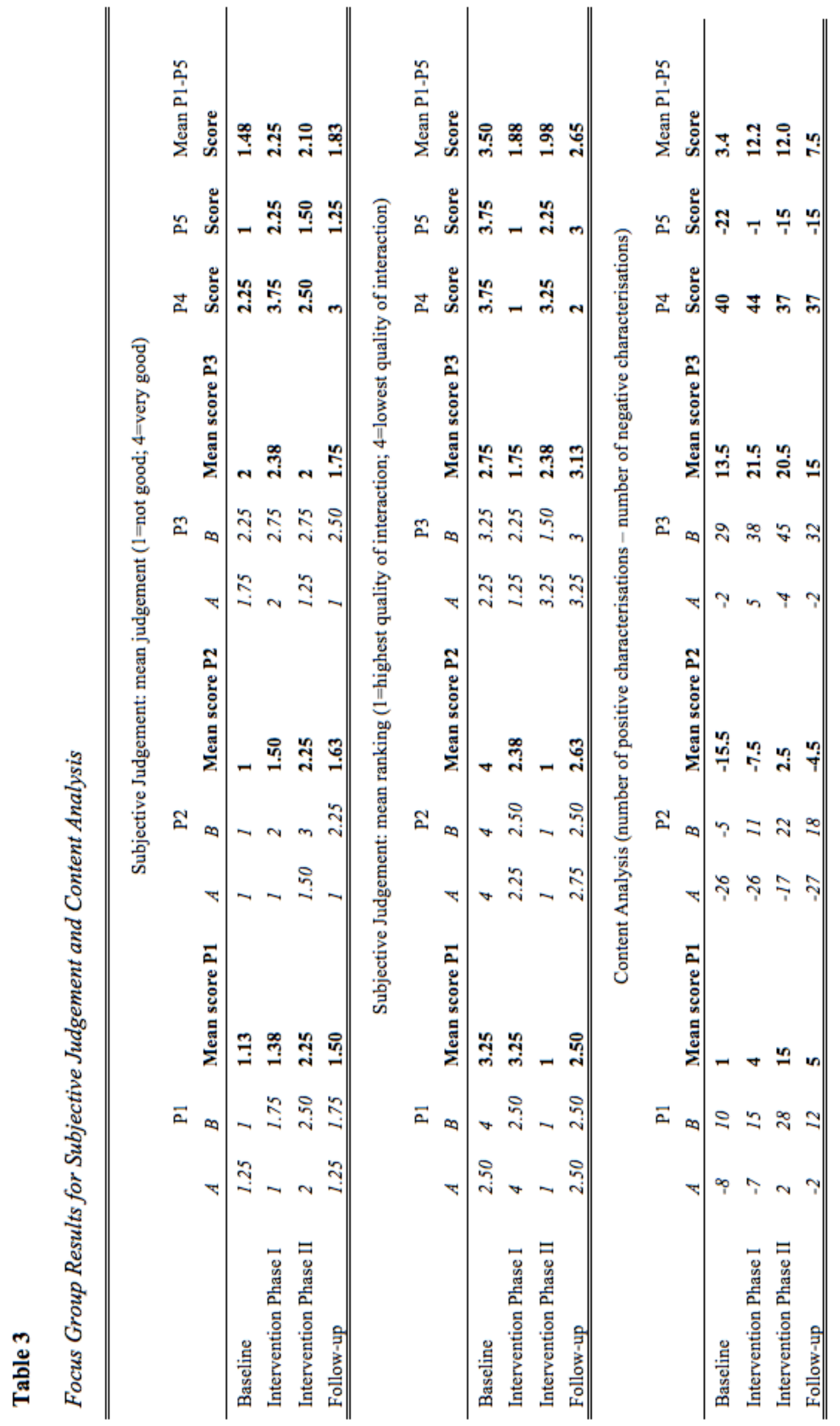


Affective involvement. No affective involvement occurred for participant 5 (see Table 2). For participant 4, affective involvement only occurred during follow-up. The other three participants were observed with two caregivers. However, no affective involvement was observed with one of the caregivers. With the other caregiver, a more regular occurrence of affective involvement was observed in three of the four study phases. The highest occurrence per participant was found at follow-up and Phase II.

\section{Effects on Interaction: Focus Group}

Table 3 presents an overview of the focus group results, including the subjective judgement of quality of interaction and ranking of the study phases, as well as the results of the content analysis. Both the scores per participant and the mean scores across participants are presented.

Subjective judgement. The mean subjective judgement scores in the right-hand column of Table 3 show that the quality of interaction was judged highest at Phase I, followed by Phase II and follow-up. The mean ranking of videos with regard to quality of interaction, in the righthand column of Table 3, follows the same pattern.

For participants 1 and 2, the quality of interaction was subjectively judged to be highest during Phase II. For participants 3, 4, and 5, the quality of interaction was judged to be highest during Phase I. The ranking of videos with regard to quality of interaction found the same results.

Content analysis. The results of the content analysis (see Table 3) suggest that the quality of interaction was highest during Phase I, followed by Phase II. The quality of interaction was lower during follow-up than during the intervention, but higher than during baseline. Participants 1 and 2 had the best results during Phase II, whereas the best result for participants 3, 4, and 5 were found during Phase I. This corresponds with the results from the subjective judgement.

As can be seen in Table 3, participants 2 and 5 had negative scores across the study (except for Phase II for participant 2). This means that the discussion about the quality of interaction included more negative than positive characterisations.

\section{Effects on Bodily Emotional Traces}

Table 4 shows the number of expressions based on a BET that were observed for the five participants. For baseline and follow-up, the absolute number is presented. For Phases I and II, the mean number of the two recordings included in the analysis is presented. Table 4 also presents the percentage of expressions based on a BET that were noticed by the caregiver. 
Table 4

Mean Number of Expressions Based on a BET and Percentage Recognised by the Caregiver

\begin{tabular}{llllllll}
\hline & & P1 & P2 & P3 & P4 & P5 & Mean P1-P5 \\
\hline Baseline & Expressions & 0 & 0 & 2 & 0 & 0 & 0.4 \\
& Recognised (\%) & - & - & 0 & - & - & 0 \\
Intervention & Expressions & 0.5 & 1.5 & 1 & 0 & 1 & 0.8 \\
Phase I & & & & & & & \\
& Recognised (\%) & 0 & 0 & 0 & - & 0 & 0 \\
Intervention & Expressions & 0.5 & 1 & 2.5 & 2 & 0 & 1.2 \\
Phase II & Recognised (\%) & 0 & 0 & 60 & 75 & - & 50 \\
& Expressions & 0 & 3 & 2 & 0 & 0 & 1 \\
Follow-up & Recognised (\%) & - & 0 & 100 & - & - & 40 \\
& & & & & & &
\end{tabular}

Overall, a small number of expressions based on a BET was found across the participants and study phases $(n=27)$. Across participants, the occurrence of expressions based on a BET was lowest at baseline and highest during Phase II. The differences between phases were small. Expressions based on a BET occurred for four participants during Phases I and II, for two participants during follow-up, and for one participant at baseline.

Before the start of BET training, the caregivers recognised none of the expressions. During Phase II and follow-up (after the start of BET training), caregivers recognised the expressions in $50 \%$ ( 6 out of 12 ) and $40 \%$ ( 2 out of 5 ) of the cases, respectively.

\section{Social Validity}

Overall, caregivers positively evaluated the intervention study. Coaching caregivers with the aim of improving interaction between caregivers and people with CDB and an ID was evaluated as "good" by three caregivers and "very good" by five (possible answers: very $\mathrm{bad} / \mathrm{bad} /$ sufficient/good/very good). The caregiver's role in setting the intervention aims and choosing the activity being recorded was evaluated as "good" by seven caregivers and as "very good" by one (possible answers: very bad/bad/sufficient/good/very good).

Different parts of the intervention were evaluated as more or less well performable. For instance, affective involvement was evaluated as "difficult" by five caregivers, whereas confirmation was evaluated as "difficult" by only one caregiver. Caregivers differed in how they evaluated the difficulty of recognising expressions based on a BET, ranging from "very difficult" to "very easy" (possible answers: very difficult/difficult/well performable/ easy/very easy). Individual coaching with video analysis was evaluated as "effective" by three 
caregivers and as "very effective" by five (possible answers: not effective at all/not effective/somewhat effective/effective/very effective). Finally, seven caregivers indicated that the change in their communicative skills towards the person with CDB and an ID was "positive", while one caregiver evaluated that change as "somewhat positive". Six caregivers indicated that the change in participants' communicative skills was "somewhat positive", while two evaluated it as "positive" (possible answers: very negative/negative/somewhat positive/positive/very positive).

\section{Discussion}

This study examined the effects of a two-phase intervention program aimed at fostering harmonious interactions and increasing the use and recognition of participant expressions based on a BET. Three research questions were formulated. With regard to the first research question - to what extent does the intervention increase the quality of interaction and, more particularly, the occurrence of attention by the caregiver, attention by the participant, confirmation by the caregiver, and affective involvement between participant and caregiver? - the occurrence of all target behaviours across participants increased during the intervention. However, some of the changes were minimal and considerable variation among participants was found.

With regard to the second research question - to what extent does the intervention increase the number of expressions based on a BET made by the participant and the recognition of these expressions by the caregiver? - the number of participant expressions based on a BET increased after the interaction training, and increased further after the BET training. Caregivers' recognition of these expressions only emerged after the BET training.

The answer to research question 3 - to what extent do the effects of the intervention endure after completion of the intervention? - is not so clear. During follow-up, overall the occurrence of the target behaviours was higher than at baseline, but lower than during the intervention phase with the highest score. The only exception is affective involvement, which increased in occurrence from intervention to follow-up for three participants.

Large variations were observed in the occurrence of attention by participant, regardless of the caregiver involved. Participant 1 had a large peak in session 19. In this session she played with a rope, which kept her attention. After throwing the rope away, she and the caregiver worked together to get it back. The caregiver gestured about it. Apparently, this situation caught her attention. No general conclusions can be drawn about the cause of the variation in the occurrence of attention by participant. It would be interesting for future studies to include more participant characteristics (i.e. temperament, interests, activities that 
are motivating, alertness, and time needed for regulation of intensity) to shed more light on this question.

Confirmation by the caregiver occurred more often after intervention. Although the intervention appears to be effective for increasing the occurrence of confirmation by caregiver, there is still much room for improvement (Table 2). The mean occurrence of confirmation by caregiver was remarkably high for participant 4 . Across the study, the results on interaction for this participant-caregiver pair were good, which is a possible explanation for the high score on confirmation. It would be interesting to add initiatives taken by the participant as a target behaviour in future studies, since these initiatives give caregivers opportunities for confirmations.

The occurrence of affective involvement was low across the entire study, with a small improvement after intervention. However, the finding that it is possible to increase the occurrence of affective involvement is in line with the results of two earlier studies that aimed to increase affective involvement in interaction with people with CDB (Martens et al., 2014a; Martens et al., 2014b). Together, these three studies show that it is possible to improve the occurrence of affective involvement by coaching caregivers, despite the fact that very specific competences are needed for sharing emotions in the case of deafblindness.

The focus group results confirm that the intervention program led to an improvement in the quality of interaction. However, even after the intervention, the quality of interaction was subjectively judged by a focus group to be "not good" (1) and "moderate" (2) on a 4-point scale ranging from 1 ("not good") to 4 ("very good"), after discussing the quality of interaction in general and different aspects of it (e.g. togetherness, turn taking). Also, there were still negative scores in the content analysis for participants 2 and 5 after the intervention; in these cases, the discussion about quality of interaction included more negative than positive characterisations. So, despite the increase in quality of interaction, caregivers need more coaching and training to attain a good or very good quality of interaction. Interestingly, participants 2 and 5 had the lowest mean occurrence of attention by caregiver at baseline and a negative score in the content analysis, suggesting a relationship between attention by caregiver and quality of interaction.

The results indicate that most participants regularly made expressions based on a BET. However, they also clearly indicate that caregivers require coaching to recognise these expressions: the caregivers recognised none of the participants' expressions before they received the BET training. After receiving just two 45-minute training sessions, the caregivers recognised up to half of all expressions based on a BET. However, two caregivers still did not recognise any expression based on a BET after the training. One of the caregivers who did recognise them after the training evaluated this as very difficult. The number of expressions based on a BET increased after the coaching. Caution is needed in interpreting this result, since the total number of expressions across participants and phases of the study was small. 
Overall, caregivers might profit from an extension of BET training, giving them more time to become familiar with the concept and to reflect upon themselves.

When looking at the overall results for the individual participants, it seems that the effect of the intervention program was highest for participants 2 and 5. A possible reason is the baseline score for these participants, leaving room for improvement. Subjective judgement of the quality of interaction by the focus group members was "not good" for these participants. The occurrence of attention by caregiver at baseline was low when compared to the other participants. The intervention program turned out to be effective for improving these scores for participants 2 and 5. Overall, according to the subjective judgement of the members of the focus group, further improvement of the interaction is possible for all participants.

\section{Limitations and Directions for Future Research}

A multiple-baseline design was used to draw conclusions about the effects of the intervention program across participants. However, since the intervention program was applied to relatively few participants, the generalisability of the findings to other people with CDB and an ID is restricted. Replication of the intervention is recommended (Barlow et al., 2009).

The use of a two-phase intervention program limits the possibilities to draw conclusions regarding the exact effects of the two separate phases of the intervention (i.e. the interaction training and the BET training). Keeping this limitation in mind, the results seem to suggest that the two training phases strengthen each other. For instance, after the BET training, the occurrence of attention by caregiver and attention by participant increased. An explanation for the increase in attention by caregiver might be that the BET training teaches caregivers to be very observant, leading to more attention. An explanation for the increase in attention by participant might be that the introduction of a new element in a routine situation causes the participant to be attentive. Also, although the BET training was Phase II of the intervention program, the occurrence of participant expressions based on a BET already increased after the interaction training (Phase I). This might be because a good quality of interaction forms a good basis for the occurrence of participant expressions based on a BET (Bloeming-Wolbrink, 2007; Daelman, 2003). However, the recognition of participant expressions based on a BET did not occur until the start of the BET training. So it seems that caregivers require specific knowledge to recognise these expressions.

The results provide some evidence for the surplus value of the two-phase intervention program. The interaction training and the BET training seem to strengthen each other. However, some caution is needed since the occurrence of confirmation by caregiver decreased from Phase I to Phase II. It could be that giving confirmation is more difficult than, for example, giving attention. Combined with a difficult subject like BETs, caregivers probably need more time to internalise the use of all these elements. 
Working with a focus group was added as a tool to evaluate interaction quality, next to the observation of categories of interactive behaviour. Both the coding of observation categories and the judgements of focus group members provided the same pattern of results. A valuable contribution of the focus group is that it not only provided information about the effect of the intervention program on the frequency of interactive behaviours, but also about the quality of interaction as judged by the focus group members. As the results show, an increase in the occurrence of categories of interactive behaviour does not necessarily mean that the quality of interaction is good. So the focus group results provide a very valuable context for interpreting the meaning of the coding results.

In this study, expressions were coded as expressions based on BETs when three criteria were met. One of the criteria was that the person is not paying attention to the surroundings, assuming that expressions based on BETs are neither social nor communicative when they emerge. But what if a person is very expressive and focused on other persons? It might be that this expression then develops while interacting with others. To further explore the BET concept, it would be interesting for future studies to code all expressions of thinking that are judged to refer to earlier experiences in a bodily way, also when the person is paying attention to their surroundings.

\section{Implications for Practice}

The results of this study show that this intervention, aimed at improving caregivers' competencies and skills, had a positive effect on their interaction with people with CDB and an ID. The use of video-feedback is a powerful coaching tool, also for helping caregivers recognize expressions based on a BET. Prior to the BET training, none of the expressions based on a BET was recognized by the caregiver. After only two coaching sessions, the caregivers did recognize expressions based on a BET. This stresses the importance of coaching on the topic BETs in daily practice.

The coaching was effective and was evaluated positively by the caregivers. The fact that there is still much room for further improvement in interaction illustrates the need for continuous coaching of caregivers. This need is further stressed by the fact that the improvements after intervention were not stable; during follow-up, the occurrence of most target behaviours was higher than at baseline, but lower than during the intervention phase with the highest score. Only the results for affective involvement showed an improvement from intervention to follow-up for the majority of participants.

This study was the first to examine the effects of BET training on the use and recognition of participants' expressions based on a BET. Expressions based on a BET are bodily expressions such as touching a location on the body, making a movement, or replicating a sensation. Since expressions of persons with CDB and an ID are often idiosyncratic and subtle, and are not always used consistently, reaching qualitative communication is difficult. 
Recognition of expressions based on a BET is useful in the meaning-making process and in reaching qualitative communication, since recognising these expressions helps the communication partners recognise bodily, idiosyncratic expressions. When making an expression based on a BET, the intention of the person with CDB and an ID is not communicative; the expressions can be seen as inner speech. However, by confirming the expression, the communication partner might start a communicative sequence. Also, the expressions reflect which elements of activities left impressions on the person with CDB and an ID, which gives caregivers information about what activities to offer and how to offer them. Offering activities in such a way that they are interesting and meaningful to the person with CDB and an ID helps in reaching harmonious interaction.

The two-phase intervention program presented here improved interaction and helped caregivers recognise the participants' unconventional expressions. This brought sighted and hearing people one step closer to the world of people with CDB and an ID, and subsequently closer to future harmonious interaction and qualitative communication. 


\section{References}

Aitken, K. J., \& Trevarthen, C. (1997). Self/other organization in human psychological development. Development and Psychopathology, 9, 653-677. doi:10.1017/s0954579497001387

Barlow, D. H., Nock, M. K., \& Hersen, M. (2009). Single case experimental designs. Strategies for studying behavior change. Boston, MA: Pearson Education.

Bjerkan, B. (1996). When do congenital deafblinds communicate? On the distinction between communication and other types of social contact. In M. Laurent (Ed.), Communication and congenital deafblindness. The development of communication. What is new? (pp.179-194). Suresnes, France: Centre national de Suresnes.

Bloeming-Wolbrink, K. A. (2007). What is on your mind? Expressions based on a Bodily Emotional Trace (BET) in the communication with persons who are congenitally deafblind. (Unpublished master's thesis). University of Groningen, Groningen, the Netherlands.

Bloeming-Wolbrink, K. A., \& Janssen, M. J. (2010). Sociale Validiteitsschaal [Social Validity Scale]. Unpublished manuscript.

Bloeming-Wolbrink, K. A., Janssen, M. J., Ruijssenaars, W. A. J. J. M., Menke, R., \& RiksenWalraven, J. M. (2015). Effects of changes in life circumstances on interaction and communication in adults with congenital deafblindness and an intellectual disability. British Journal of Visual Impairment, 33, 31-44. doi:10.1177/0264619614558429

Brown, E., \& Snell, M. E. (1993). Measurement, analysis and evaluation. In M. E. Snell (Ed.), Instruction for students with severe disabilities (pp.152-183). New York, NY: MacMillan.

Bruce, S. M. (2005). The impact of congenital deafblindness on the struggle to symbolism. International Journal of Disability, Development and Education, 52, 233-251. doi:10.1080/10349120500252882

Daelman, M. (2003). Een analyse van de presymbolische communicatie bij blinde kinderen met een meervoudige handicap. Een aanzet tot orthopedagogisch handelen [An analysis of presymbolic communication in blind children with a multiple impairment. A starting point for orthopedagogical practice]. (Unpublished doctoral dissertation). Katholieke Universiteit Leuven, Leuven, Belgium.

Daelman, M., Janssen, H. J. M., Ask Larsen, F., Nafstad, A., Rødbroe, I., Souriau, J., \& Visser, T. (2001). Congenitally deafblind persons and the emergence of social and communicative interaction. Phase III: the formation of meaning. Working paper of the Deafblind 
International Communication Network. Retrieved from http://www.nordicwelfare.org/ PageFiles/7075/CNUS02_web.pdf

Dalby, D. M., Hirdes, J. P., Stolee, P., Strong, J., Poss, J., Tjam, E. Y., \& Ashworth, M. (2009). Characteristics of individuals with congenital and acquired deaf-blindness. Journal of Visual Impairment \& Blindness, 103, 93-102.

Damen, S., Janssen, M. J., Huisman, M., Ruijssenaars, W. A. J. J. M., \& Schuengel, C. (2014). Stimulating intersubjective communication in an adult with deafblindness: a single-case experiment. Journal of Deaf Studies and Deaf Education, March 2014, 1-19. doi:10.1093/deafed/enu006

Damen, S., Janssen, M. J., Ruijssenaars, W. A. J. J. M., \& Schuengel, C. (2015). Intersubjectivity effects of the high quality communication intervention in people with deafblindness. Journal of Deaf Studies and Deaf Education, 20(2), 191-201. doi:10.1093/deafed/env001

Dammeyer, J. (2010). Interaction of dual sensory loss, cognitive function, and communication in people who are congenitally deaf-blind. Journal of Visual Impairment \& Blindness, 104, 719-725.

Diamond, L. M., \& Aspinwall, L. G., (2003). Emotion regulation across the life span: An integrative perspective emphasizing self-regulation, positive affect, and dyadic processes. Motivation and Emotion, 27, 125-156. doi:10.1023/A:1024521920068

Hart, P. (2010). Moving beyond the common touchpoint: Discovering language with congenitally deafblind people (unpublished doctoral dissertation). University of Dundee, Dundee, Scotland.

Horner, R. H., Carr, E. G., Halle, J., Odom, S., \& Wolery, M. (2005). The use of single-subject research to identify evidemce-based practice in special education. Council for Exceptional Children, 71, 165-179.

Janis, I. L. (1965). The problem of validating content analysis. In H. D. Lasswell et al. (Eds.), Language of politics (pp.55-82). Cambridge, MA: MIT Press.

Janssen, M. J., Riksen-Walraven, J. M., \& Van Dijk, J. P. M. (2003a). Toward a diagnostic intervention model for fostering harmonious interactions between deafblind children and their educators. Journal of Visual Impairment \& Blindness, 97, 197-214.

Janssen, M. J., Riksen-Walraven, J. M., \& Van Dijk, J. P. M. (2003b). Contact: Effects of an intervention program to foster harmonious interactions between deafblind children and their educators. Journal of Visual Impairment \& Blindness, 97, 215-229.

Johnson, M. (2008). What makes a body? The Journal of Speculative Philosophy, 22, 159-169. doi:10.1353/jsp.0.0046 
Martens, M. A. W., Janssen, M. J., Ruijssenaars, W. A. J. J. M., \& Riksen-Walraven, J. M. (2014). Introducing an intervention model for fostering affective involvement with persons who are congenitally deafblind. Journal of Visual Impairment \& Blindness, 108, 29-41.

Martens, M. A. W., Janssen, M. J., Ruijssenaars, W. A. J. J. M., Huisman, M., \& Riksen-Walraven, J. M. (2014a). Intervening on affective involvement and expression of emotions in an adult with congenital deafblindness. Communication Disorders Quarterly, 36, 12-20. doi:10.1177/1525740114526926

Martens, M. A. W., Janssen, M. J., Ruijssenaars, W. A. J. J. M., Huisman, M., \& Riksen-Walraven, J. M. (2014b). Applying the intervention model for fostering affective involvement with persons who are congenitally deafblind: An effect study. Journal of Visual Impairment \& Blindness, 108, 399-413.

Nourbakhsh, M. R., \& Ottenbacher, K. J. (1994). The statistical analysis of single-subject data: A comparative examination. Physical Therapy, 74, 768-776.

Pérez-Pereira, M., \& Conti-Ramsden, G. (1999). Language development and social interaction in blind children. Hove, UK: Psychology Press.

Prain, M. I., McVilly, K. R., \& Ramcharan, P. (2012). Being reliable: issues in determining the reliability and making sense of observations of adults with congenital deafblindness? Journal of Intellectual Disability Research, 56, 632-641. doi:10.1111/j.13652788.2011.01503.x

Rowland, C. (Ed.), 2009. Assessing communication and learning in young children who are deafblind or who have multiple disabilities. Design to Learn Projects, Oregon Health \& Science University. Retrieved from http://www.designtolearn.com/uploaded/ pdf/DeafBlindAssessmentGuide.pdf

Seys, D. M. (1987). Kwaliteit van zorg: zorg voor kwaliteit. [Quality of care: Care for quality]. (PhD thesis). Radboud University, Nijmegen, the Netherlands.

Sroufe, L.A. (1995). Emotional development. The organization of emotional life in the early years. Cambridge, UK: Cambridge University Press.

Stellingwerf, I. (2012). Waar denk je aan..? De ontwikkeling van een observatiesysteem voor Bodily Emotional Traces bij personen met congenitale doofblindheid [What are you thinking of..? The development of an observational system for Bodily Emotional Traces in persons with congenital deafblindness]. (Unpublished master's thesis). University of Groningen, Groningen, the Netherlands.

Stewart, D. W., Shamdasani, P. N., \& Rook, D. W. (2007). Focus Groups: Theory and Practice (2nd ed.). London, UK: SAGE Publications. 
Trevarthen, C., \& Aitken, K. (2001). Infant intersubjectivity: Research, theory, and clinical applications. Journal of Child Psychology and Psychiatry, 42, 3-48. doi:10.1111/14697610.00701

Kitty A. Bloeming-Wolbrink, Department of Special Needs Education and Youth Care, University of Groningne, The Netherlands; e-mail: <kittybloeming@visio.org>. Marleen Janssen, Prof. Dr., Professor, Department of Special Needs Education and Youth Care, University of Groningen, e-mail: <h.j.m.janssen@rug.nl>. Wied A.J.J.M. Ruijssenaars, Professor Emeritus Department of Special Needs Education and Youth Care, University of Groningen; e-mail: <a.j.j.m.ruijssenaars@rug.nl>. J. Marianne Riksen-Walraven, PhD, Professor, Behavioural Science Institute, Radboud University Nijmegen, The Netherlands; e-mail: <m.riksen@psych.ru.nl>. 